\title{
Aging and Strategic Learning: The Impact of Spousal Incentives on Financial Literacy
}

\author{
Joanne W. Hsu ${ }^{*}$ \\ *Joanne W. Hsu is an economist at the Federal Reserve Board
}

\begin{abstract}
Women tend to be less financially literate than men, consistent with a division of labor where husbands manage finances. However, women tend to outlive their husbands. I find that older women acquire financial literacy as they approach widowhood -80 percent would catch up with their husbands by the expected onset of widowhood. These gains are not attributable to husbands' cognitive decline, as captured by cognition tests. The results are consistent with a model in which the division of labor collapses when a spouse dies: women have incentives to delay acquiring financial human capital, but also to begin learning before widowhood.
\end{abstract}

\section{Introduction}

Empirical studies have found that women tend to have lower levels of financial literacy than men (for example, Lusardi and Mitchell 2008; Fonseca et al. 2012; Kotlikoff and Bernheim 2001). This gap may reflect a division of labor within the household such that men are responsible for financial matters. However, women also tend to outlive their husbands, so they will eventually need to take over this task. Women therefore have incentives both to delay acquiring financial knowledge but also to begin learning prior to widowhood. Financial literacy is a critical form of financial knowledge that is linked to important economic outcomes, including more effective wealth management, better management of credit and debt, retirement planning, increased saving, and higher stock market participation (Hilgert, Hogarth, and Beverly 2003; Lusardi and Tufano 2009b; Lusardi and Mitchell 2007, 2009; Carlin and Robinson 2012; Van Rooij, Lusardi, and Alessie 2011). Economists view investment in human capital as a purposive process, and in this paper, I show that the acquisition of financial literacy is no different.

This paper presents a model of the human capital investment process of longer-lived spouses over the life cycle and tests its predictions using innovative new data on financial literacy and financial decision-making. The model generates three results. First, if the household finances are managed by husbands, women may rationally delay learning about finances. Secondly, investments in financial knowledge should increase as widowhood becomes more imminent; lastly, longer durations of widowhood provide additional incentives for accumulating more human capital. While I analyze the model specifically for women and 
financial literacy, the model is generalizable to any task specialized in by the shorter living spouse.

Using a cross-sectional sample that links husbands and wives, I use variation in the husbands' life expectancies to analyze how women accumulate human capital relative to their husbands, who do not have the same incentive to increase learning in old age. The results, robust to controlling for four forms of cognition that decline with age, show that women acquire financial literacy as they approach widowhood. At an estimated rate of 0.04 standard deviations per year, 80 percent of women in the sample would catch up with their husbands prior to the expected onset of widowhood.

Financial knowledge is critical due to its relationship to economic outcomes and its policy implications. Given its links with financial planning and behavior, having sufficient financial literacy is becoming even more important since the responsibility for retirement planning has shifted to individuals. Wealth management has become increasingly complex as predictable streams of retirement income from pensions have been replaced by account-type plans that need to be managed both before and after retirement. In addition, financial literacy has become a prominent policy issue in the wake of the 2008 economic crisis. ${ }^{1}$ The large numbers of foreclosures, defaults, and debt problems that arose during the housing and financial crisis highlight the costs of financial illiteracy for individuals with low and high levels of wealth. Furthermore, proposals to privatize Social Security would introduce further individual responsibility for retirement planning and require even more knowledge.

This paper makes a number of contributions. This is, to my knowledge, the first study to analyze investments in financial knowledge in a life-cycle framework. While descriptive studies have documented low levels of financial literacy, especially among women (Lusardi and Mitchell 2011, 2008; Lusardi, Mitchell, and Curto 2010, 2009; Fonseca et al. 2012; Lusardi and Tufano 2009a), they have not found an economic basis for the pattern. My finding that women acquire knowledge as they approach widowhood shows that the gender gap in financial literacy may reflect strategic responses of women to incentives over the life cycle.

Second, this paper is the first to link the financial knowledge of both members of a couple. By analyzing the spousal gap in financial literacy rather than differences between women and men in different households, I can investigate how financial knowledge relates to the division of labor over the life cycle. I also use a rich set of cognitive measures to show that the narrowing of the wife-husband gap in financial literacy reflects advances on the part of women and is unlikely to be merely an artifact of men's cognitive decline. ${ }^{2}$ This is not to say, however, that older women are sufficiently preparing for their financial future. In light of studies documenting the low levels of financial literacy among both older men and

\footnotetext{
${ }^{1}$ Older policies include the Fair and Accurate Transaction Act of 2003 which established the Financial Literacy and Education Commission, and mandates for financial education in schools implemented by many states in the 1970s (Cole, Paulson, and Shastry 2014; Bernheim, Garrett, and Maki 2001).

${ }^{2}$ The underlying assumption is that the cognitive decline of husbands is fully captured by the control variables. Section IV.C summarizes theories of intelligence and age in the psychology literature, and also details cognitive measures that exhibit declines with age, both theoretically and empirically.
} 
women (Lusardi, Mitchell, and Curto 2009), merely catching up with one's husband may not be enough to prevent the poor economic outcomes common among widows.

This paper combines ideas about the household division of labor with human capital theory. Section II provides additional background on financial knowledge as human capital in the context of the household division of labor and widowhood. Section III presents a theoretical model of the timing of a woman's investment in financial human capital over her lifetime. Section IV describes the data used, and Section V presents evidence that older women acquire financial knowledge as widowhood approaches. These effects remain even when controlling for a rich set of measures of husband's cognition. Section VI concludes.

\section{Financial Literacy, Human Capital, and Specialization}

The management of household finances is an important type of non-market production that requires its own form of human capital. One major component of this human capital is financial literacy. Public and scholarly interest in financial literacy and informed financial decision-making is increasing in part because of the poor financial outcomes that are associated with low levels of financial literacy: problems with debt (Lusardi and Tufano $2009 b$ ) and lack of retirement planning (Lusardi and Mitchell 2007, 2009), among others. At the same time, studies have found that Americans tend to display low levels of financial literacy (Bernheim 1998; Hilgert, Hogarth, and Beverly 2003; Lusardi and Tufano 2009 b). Financial illiteracy and financial mistakes are particularly widespread among older Americans (Lusardi and Mitchell 2011; Agarwal et al. 2009). Recent government policies, including the establishment of the Consumer Financial Protection Bureau, aim to increase financial literacy among the public.

As mentioned, descriptive studies have shown that women tend to have lower levels of financial literacy than men. This is true even for younger women (Lusardi, Mitchell, and Curto 2010; Chen and Volpe 2002), in spite of their gains in educational attainment. Low levels of financial literacy may not be problematic if one's partner has higher literacy and specializes in managing household finances. As Becker (1985) shows, under a number of assumptions, it is efficient for members of a household to specialize in particular tasks. However, such reliance on a partner can have serious consequences when one is unable to divide tasks among household members either before forming a household or during widowhood. ${ }^{3}$

In American households, men are usually primarily responsible for household finances. ${ }^{4}$ In the Cognitive Economics Study used in this paper, only 16 percent of couples report that the woman is the most financially knowledgeable person in the household. A person may become the financial specialist in a couple for a number of reasons. First, the person entering

\footnotetext{
${ }^{3}$ While a widow might also be able to rely on adult children, in this paper I analyze a simple human capital model, without separately analyzing its interaction with other decisions on human capital investments in children.

${ }^{4}$ Another form of non-market production is the management of health and medical matters. In the United States, women tend to specialize in these matters. Studies show between 60 to 80 percent of women are primary decision makers about health care (including selecting doctors and health insurance) for their families, with an additional 18 to 22 percent reporting making joint decisions with partners or spouses (Salganicoff et al. 2002; Salganicoff, Ranji, and Wyn 2005). Critically, however, men are much less likely to outlive a spouse and be tasked with replicating this knowledge.
} 
marriage with a greater stock of financial knowledge might be more likely to specialize; this could favor the older member of the couple, typically the man. This advantage may arise from past experience with finances, possibly through one's occupation. Educational sorting may play a role, if college-educated women were more likely to major in non-quantitative fields. A second factor may simply be the interest or enthusiasm of the specialist, or fear or avoidance on the part of the non-specialist. Third, the division of labor may also be a product of intra-household bargaining. Whatever the root causes, women tend to be less financially literate than men. Since women tend to outlive men, this division of labor cannot be sustained indefinitely.

Economists have shown that the expected duration of a household affects how labor is divided. Johnson and Skinner (1986) find that greater divorce risk increases the labor supply of women, and Stratton (2005) shows that cohabiting couples, whose relationships are typically shorter in duration than those of married couples, have less intra-household specialization in housework than married couples. While widowhood is a different form of relationship termination, it operates similarly by ending a person's ability to reap the benefits of specialization. This suggests that the nature of the division of labor within a household changes over time and therefore calls for continued investment.

Widowhood is a very likely outcome for most married women, who not only face longer life expectancies than men but are also typically younger than their husbands. According to 1995 marital status life tables, 75 percent of marriages not ending in divorce end in widowhood (Schoen and Standish 2001). Furthermore, the mean duration of widowhood in the Health and Retirement Study is about nine years (author's own calculations). Although the gender disparity in life expectancies has changed over time, widowed women still outnumbered widowed men four to one in 2009 (U.S. Census Bureau 2010). The prospect of many years without the couple's financial specialist creates incentives for women to prepare by acquiring financial knowledge. 5

The notion that financial knowledge is a form of human capital was introduced in Delavande, Rohwedder, and Willis (2008), which related the production of human capital to portfolio choice. Human capital accumulation is purposive based on its costs and benefits, and likewise, financial illiteracy can be costly for widows. Even a widow who plans to delegate the management of her finances to a professional or a relative needs enough knowledge to choose someone trustworthy and to recognize if she is being bilked. If she manages her own finances, she needs to be knowledgeable enough to distinguish fraudulent offers from legitimate ones. On the other hand, a widow who recognizes her lack of knowledge but does not trust any individuals or financial institutions may lose potential gains by keeping all of her money in cash. Financial illiteracy can also lead to anxiety about money. A woman with insufficient financial knowledge may find herself in widowhood

\footnotetext{
${ }^{5}$ This paper focuses on the incentives created by the prospect of widowhood faced by women. Incentives may arise from other aspects of gender differences in aging and mortality. For example, a woman may plan on being responsible for finances when her husband becomes cognitively or physically impaired due to aging, if she believes these her husband's decline will occur before her own. Hsu and Willis (2013) examine the role of cognitive decline and dementia on financial decision-making using a longitudinal dataset. Because the empirical analysis in this paper employs a single cross-section, I cannot identify declines of husbands relative to declines of wives.
} 
without a firm understanding of how much she can afford to spend, what her holdings are, or how quickly to decumulate during widowhood.

Since investment decisions and payoffs are realized over the life cycle, an important aspect of human capital accumulation is its timing. Mincer and Polachek (1974) argue that the human capital investments and time allocation of individuals will be influenced by expectations of future family and market activities. In most applications such as formal education and on the job training (Ben-Porath 1967), it is advantageous to invest early to capture the longest stream of benefits. On the other hand, some investments (such as religious devotion as investment in the afterlife, studied by Azzi and Ehrenberg 1975) may not yield benefits until much later in life, so the payoffs to such investments should increase with age. Similarly, household specialization creates delays in the returns to investing in knowledge related to the spouse's tasks.

In this paper, I develop a simple model to analyze the timing of human capital investments in the spouse's tasks and the effects of differing time horizons arising from gender differences in life expectancies. Using an innovative new dataset, I study the financial knowledge of husbands and wives, and in doing so I am able to learn more about an aspect of household production that is not well understood. One theme underpinning the human capital literature is that investments are purposive, and I show that the timing of investments in financial human capital is purposive as well.

\section{Theoretical Framework}

This section presents a simple model to build intuition for the woman's decision to accumulate human capital related to tasks in which she does not specialize. Consider a time span that begins with marriage $(t=0)$ and lasts until the woman dies in period $T$. The woman will outlive her husband, who passes away at time $D .^{6}$ Therefore, widowhood spans from time $D$ to $T$. Assume the husband specializes in household finances from the beginning of the marriage.

Assume further that non-wage financial resources can only be used if at least one person in the household has financial knowledge. A new widow with no financial knowledge will not be able to access any non-wage financial resources until she acquires some financial knowledge. ${ }^{7}$ In this case, consumption smoothing implies that a widow will want at least some financial knowledge at the time of widowhood. This is most realistic in a situation in which the husband was wholly responsible for all household financial matters.

A woman only begins to use this financial knowledge after her husband dies, after which the returns to her stock of financial human capital $K$ are $v(K)$ annually until her death. The present discounted value (after depreciation) of a marginal unit of financial human capital over the course of her life is then:

\footnotetext{
${ }^{6}$ This model assumes the husband's time of death is known with certainty. With a model using a probabilistic survival function to reflect uncertain mortality, all the predictions analyzed below remain, so for clarity the simpler model is presented here.

${ }^{7}$ Or, one could hire a professional to manage finances, which incurs a monetary rather than time cost. Doing so also requires enough knowledge to evaluate the abilities or trust worthiness of potential advisors and to monitor their activities.
} 


$$
P_{t}=\left\{\begin{array}{cc}
{[\beta(1-\delta)]^{D-t} \sum_{j=0}^{T-D} \beta^{j} v^{\prime}\left(K_{t}\right)} & \text { if } t<D \\
\sum_{j=0}^{T-t} \beta^{j} v^{\prime}\left(K_{t}\right) & \text { if } t \geq D
\end{array}\right.
$$

where $\beta$ is the subjective discount factor and $\delta$ is the depreciation rate $^{8}$ of human capital. Prior to widowhood, the value of a marginal increase in human capital is the present value of the stream of annual benefits realized during widowhood for a total of $T-D$ years, discounted by the number of years a woman must wait until the stream begins ( $D-t$ years). At time zero, the present value of the benefits are low due to the $D$-year delay until widowhood. The value increases as a woman approaches widowhood, at which point it declines because of the decreasing number of years the knowledge can be used. Assuming that units of human capital have a constant marginal product that is independent of the number of units newly acquired or of the current stock of knowledge, the time path of $P_{t}$ is upward and convex until it peaks at time $D$, when it declines concavely. $P_{t}$ can therefore be interpreted as the demand for financial human capital at time $t$. This demand is time variant, so a marginal cost curve is required to pin down the time-path of human capital investments. Time is allocated to acquiring financial knowledge at the expense of other activities. In its simplest form, assume that this marginal cost curve is upward sloping and fixed over time, with its position determined by underlying ability. As $P_{t}$ shifts upward, a woman will acquire more human capital until widowhood (with the rate of accumulation increasing with age), after which point she will stop, as the costs exceed the benefits. She will therefore use whatever human capital she acquired by time $D$ for the duration of widowhood.

The derivative of $P_{t}$ with respect to the time to widowhood $D$ is

$$
\frac{d P_{t}}{d D}=[\beta(1-\delta)]^{D-t} \frac{1}{1-\beta}\left(\beta^{T} \ln \beta+\left(\beta-\beta^{T+1-D}\right) \ln [\beta(1-\delta)]\right)<0 .
$$

The negative sign of this derivative confirms the intuition that as one approaches widowhood, the marginal benefit increases. The derivative with respect to the length of widowhood $(T-D)$, holding $D$ constant:

$$
\frac{d P_{t}}{d(T-D)}=-[\beta(1-\delta)]^{D-t} \frac{1}{1-\beta} \beta^{T+1-D} \ln \beta>0 .
$$

Therefore, the shorter the time to widowhood, the greater the demand for financial human capital. The longer the duration of widowhood, the greater the demand for financial knowledge. The ratio of the magnitude of the two derivatives is

\footnotetext{
${ }^{8}$ This depreciation rate reflects the assumption that human capital is not used until widowhood. If human capital depreciates both before and after widowhood, or if it depreciates faster prior to widowhood than during, all of the subsequent predictions still hold.
} 


$$
\frac{\frac{d P_{t}}{d D}}{\frac{d P_{t}}{d(T-D)}}=\frac{\beta^{T} \ln \beta+\left(\beta-\beta^{T+1-D}\right) \ln [\beta(1-\delta)]}{\beta^{T+1-D} \ln \beta} .
$$

Assuming $\beta=0.97$ and $\delta=0.03$, with $D$ and $T-D$ the expected time to and expected length of widowhood, respectively, the ratio in my sample ranges from 1.3 to 2.8 , with a mean of 1.7..$^{9}$ The ratio is larger the more imminent widowhood is and the longer its duration. The ratio is also larger the greater the depreciation rate of human capital and the lower the discount factor $\beta$. Therefore, the effect of the time to widowhood on the acquisition of financial literacy should be greater in magnitude than the effect of the duration of widowhood.

Lastly, a large depreciation rate $\delta$ of human capital also increases the incentive to delay the investment. In the context of financial knowledge, depreciation may take the form of specific knowledge becoming obsolete as financial institutions and rules change. In sum, the model predicts that a woman will acquire financial knowledge very slowly at the beginning of the marriage and delay larger investments in human capital. The rate of investing will increase as the expected time of widowhood approaches. After her husband dies, she takes charge of the finances and accrues payoffs to her financial knowledge. This framework is described in terms of financially specializing husbands and their wives, but it can easily apply to any couple in which one person outlives the other and the shorter living spouse specializes in at least one task. The fact that women have longer life expectancies than men and are typically younger than their husbands makes it easier to test the implications of such a model. Had the longer-living spouse specialized in household finances from the beginning, the time-path of financial human capital investments would more closely follow the Ben-Porath prediction front-loaded investments that decline over time. ${ }^{10}$ Other models, such as those assuming hyperbolic discounting or other behavioral models, can be used to analyze these investments in human capital, but I will show that the standard model presented here is consistent with empirical patterns.

\section{Data}

The empirical analysis uses data from the Cognitive Economics Survey (CogEcon), ${ }^{11}$ an innovative new survey of a national sample of persons 51 and older and their spouses regardless of age. The first wave, administered in the spring and summer of 2008 , includes a 24 question battery on financial literacy, detailed measures of income, wealth and portfolio allocation plus measures of risk tolerance, self-assessed financial knowledge, and several questions on decision-making.

\footnotetext{
${ }^{9}$ Gourinchas and Parker (2002) estimate a structural model using the Consumer Expenditure Survey and find that high school graduates have a discount factor of 0.96 and college graduates have a discount factor of 0.97 .

${ }^{10}$ The Ben-Porath model includes a key feature that I have dropped for simplicity: the ability of the current capital stock to increase the productivity of subsequent investments. This feature allows his model to generate a time path that begins with full time learning and drops sharply, in contrast to the smooth concave function generated by mine.

${ }^{11}$ The Cognitive Economics Study (2012) is supported by National Institute on Aging program project P01-AG026571, "Behavior on Surveys and in the Economy Using HRS," Robert J. Willis, PI. More information about CogEcon is available at http://ebpprojects.isr.umich.edu/CogEcon/surveys.html.
} 
These respondents also participated in the Cognition and Aging in the USA study (CogUSA $)^{12}$ which includes an extremely detailed cognitive assessment. In addition, respondents were asked questions about their subjective expectations, including their subjective survival probabilities. The combined survey allows for the linking of cognitive measures and the economic measures collected in CogEcon. Furthermore, unlike many other surveys that collect financial data from only one person per household, this study collects measures of financial decision-making and financial knowledge from both husbands and wives.

Because the model predicts that women will increase their acquisition of financial knowledge prior to the death of their spouses, the empirical analysis requires measures of the expected time and length of widowhood. I compute these using survival probabilities drawn from 2004 period life tables published by the National Center for Health Statistics. ${ }^{13}$ As a robustness check (see the online appendix, found at http://jhr.uwpress.org/), I use alternative survival measures from subjective survival questions as well as objective survival probabilities predicted using the Health and Retirement Study (HRS), a much larger panel survey of similarly-aged individuals. ${ }^{14}$ In an additional robustness check, I also analyze longitudinal data on proxies for financial literacy on the HRS.

\section{A. Sample and Demographics}

CogEcon collects information from 748 unique households, ${ }^{15}$ defined as couples or individuals without partners. Both members of 224 couples participated in the survey (448 respondents), including the financial literacy battery. The remaining respondents are unmarried individuals or coupled respondents with partners about whom we have partial or no information due to complete or partial non-response. Further information about response rates and the derivation of the analysis sample can be found in the online appendix. Table 1 reports the demographic characteristics of all respondents with spouses in the sample. The average age of women is 60.5 years, with men about 2.5 years older. Because the analysis focuses on couples, and requires that both members of the couple complete the survey, the analysis sample is relatively highly educated, and of higher income than in general for this age group, when including single individuals such as widows and widowers.

The marriage is the individual's first in a majority of cases, and respondents have on average 2.7 children. According to life tables, the average life expectancy of women is 24 years, while it is 19 years for their husbands. Men have slightly more education than women in this sample. Only 16 percent of wives report being most knowledgeable about finances.

\footnotetext{
${ }^{12}$ The Cognition and Aging in the USA Study (2011) is sponsored by NIA grant R37 AG007137, "Assessing and Improving Cognitive Measurements in the HRS," John J. McArdle, PI. More information about CogUSA is available at http://cogusc.usc.edu. ${ }^{13}$ These life tables, by age, sex, and race, are found in Tables 5, 6, 8 and 9 (Tables 2 and 3, which are not race-specific, are used for respondents who specify a race other than black or white, or decline to specify) from Arias (2007) and were the most up-to-date versions published by the National Center for Health Statistics at the time the CogEcon Survey was fielded.

${ }^{14}$ The HRS (Health and Retirement Study 2014) is sponsored by the National Institute on Aging (grant number NIA U01AG009740) and is conducted by the University of Michigan. Some variables were provided by the RAND HRS Data (2014).

${ }^{15}$ Three same-sex couples are excluded as there are no established patterns that indicate that the shorter living member is more likely to be the financial specialist in such couples.
} 


\section{B. Outcomes of Interest: Financial Knowledge}

The survey includes a financial literacy battery of 24 questions. Each presents a statement, and the respondent is asked whether s/he thinks the statement is true or false, and how sure s/he is of that response on a 12-point scale based on her/his degree of certainty (see Figure A1 in the online appendix). Questions are converted to the true version so that the scale can be interpreted as " $0 \%$ surely (correct answer)" to " $100 \%$ surely (correct answer)." The responses are re-scaled to a zero-one scale. ${ }^{16}$ An individual's financial sophistication score is calculated by taking each respondent's mean score across questions in the battery and normalizing across all survey respondents. A within-couple relative score is computed using the wife-husband difference in normalized mean scores.

Topics covered include interest compounding, diversification and risk, financial terms, stock market concepts, taxation, and inflation. ${ }^{17}$ To account for the fact that not all respondents participate in the stock market, some analyses will employ a basic literacy score that excludes the fifteen stock related questions. As can be seen in the summary statistics in Table 2, men have, on average, higher levels of financial literacy than women whether or not stock questions are included.

\section{Cognitive Ability and Other Control Variables}

While the model emphasizes the effect of a spouse's mortality on the division of labor, a spouse's declining cognition or health status are other factors that would similarly necessitate learning about his tasks. Summary statistics for these factors are reported in Table 2.

One of the most widely accepted theories of cognitive abilities is that of fluid and crystallized intelligence (Gf-Gc theory) (Cattell 1941; Horn 1965; Horn and Cattell 1966, 1967). Primary abilities are divided into two broad dimensions: fluid intelligence (Gf) and crystallized intelligence $(\mathrm{Gc})$. Fluid intelligence represents reasoning abilities that result from biological influences on intellectual development, such as heredity or brain injuries. Crystallized intelligence refers to the use of accumulated knowledge and skill and represents the results of educational investments and experience rather than underlying ability. The distinction between fluid and crystallized intelligence is similar to the notion of ability versus human capital in labor economics.

Financial literacy can be interpreted both as a form of human capital as well as a form of crystallized intelligence. While crystallized intelligence tends to increase through the accumulation of knowledge, fluid intelligence peaks early in life and declines over the remaining life cycle. Psychologists have verified that fluid intelligence declines with age (McArdle, Fisher, and Kadlec 2007; Verhaeghen and Salthouse 1997). Other broad cognitive abilities within the Gf-Gc framework that decline strongly with age include processing speed and memory (McArdle et al. 2002). Measures of speed typically share about 75 percent of

\footnotetext{
${ }^{16}$ This scoring method penalizes confident incorrect answers ("100\% surely false/true") more heavily than incorrect guesses, and similarly rewards confident correct responses. Consistent with patterns found by Lusardi, Mitchell, and Curto (2009), women choose "guess true/false" more frequently than men. However, binary correct-incorrect scores yield similar results for all analyses.

${ }^{17}$ For more details about the battery, see the online appendix.
} 
the age-related variance of other measures of cognition (Salthouse 2000). Declines in speed and memory have even been shown to precede declines in fluid intelligence (McArdle et al. 2000). ${ }^{18}$ Measures of fluid intelligence, memory, and processing speed can thus be used to control for the cognitive decline of respondents and to conduct robustness checks.

Fluid intelligence is measured using the Woodcock-Johnson III (WJ-III) Number Series test. Respondents are given a sequence of numbers with a missing number, and they are asked the value of the missing number. The WJ-III Visual Matching test, a measure of processing speed, asks respondents to locate the two identical numbers within a row of six numbers. Memory is measured using the WJ-III Auditory Working Memory test. After listening to a series of numbers and words, the respondent is asked to recall in sequential order first the objects then the numbers. Lastly, the Wechsler Adult Intelligence Scale (WAIS) Matrix Reasoning test is a measure of non-verbal fluid intelligence. The respondent is presented with an incomplete matrix or series of images or designs and is asked for the missing image. The scores used by psychologists are scaled using large external norming samples, but here I standardize the scores among all CogUSA respondents (pooling together men and women) for easier interpretation. In the analysis sample, men tend to have higher Number Series scores, but lower processing speed and memory scores, than women (see Table 2). ${ }^{19}$

Additional cognition measures can be used in place of financial knowledge as outcomes in falsification tests. In addition to the aforementioned measures of cognition, I also use measures of verbal reasoning and numeracy/mathematical skill. The WJ-III Verbal Analogies test measures the respondent's ability to reason using lexical knowledge; it is a verbal measure of fluid intelligence. Lastly, numeracy is measured with the WJ-III Calculation test. The Number Series and Calculation tests are the two scores that are most highly correlated with financial literacy.

In addition to his cognitive decline, a husband's poor physical health may also contribute to a woman taking over his tasks. One overall measure of health is the question, "Would you say your health is excellent, very good, good, fair, or poor?" This self-rated health measure is coded from 1 (for poor) and 5 (for excellent). Women rate their health slightly higher than men (see Table 2), though this difference is not statistically significant.

Lastly, I control for wealth using the decile of household net worth, as reported by the CFO of the household. ${ }^{20}$ Because household net worth is computed as the sum of numerous questions on the survey and is subject to item nonresponse, imputation variability, and so forth, I use deciles computed at the household level (including singletons) instead of the dollar value of net worth.

\footnotetext{
${ }^{18}$ Furthermore, episodic memory is typically among the first cognitive functions to deteriorate during aging (Backman, Small, and Wahlin 2001).

$19^{2}$ The gender difference in Matrix Reasoning scores is not statistically significant.

${ }^{20}$ The algorithm for determining whose wealth report to use is described in the online appendix. Total wealth is the sum of housing wealth, tax-advantaged financial wealth, and non-tax-advantaged financial wealth (including net business equity, vehicles, and other assets), net of debt (including all mortgages and loans on housing, auto loans, and other debts like medical loans, student loans, and personal loans. The present value of defined benefit pensions is not available.
} 


\section{Empirical Results and Discussion}

\section{A. Background: the CFO and the Household Division of Labor}

The most direct question related to household division of labor asks "Which member of the immediate family is most knowledgeable about your family's assets, debts, and retirement planning?" Respondents may specify "me," "my spouse/partner," "both me and my spouse/ partner," or "someone else in the family" as the household's "Chief Financial Officer" (CFO). About 16 percent of women in couples report being most knowledgeable, and less than half report being at least equally knowledgeable (see Table 1).

A unique advantage of the CogEcon study is that it interviews both members of a couple whenever possible. Only 4 percent of couples provide contradictory responses; a crosstabulation of the two members' responses to the question about who is the household CFO is reported in Table A1 in the online appendix. Because of the small number of couples with inconsistent answers, the analysis will ignore these discrepancies and will consider the woman's response as representative of the couple.

To verify that the question on financial knowledge provides information about the division of labor, I investigate how financial knowledge relates to financial decision-making using the question "Who (among members of your immediate family) makes the decisions about how to save for retirement and other large expenses?" Responses to the two questions are highly correlated. Among those in couples, over 60 percent of respondents name the same person(s) as the most knowledgeable as well as the decision-maker. Over one-third of respondents state that both members make decisions while only one is most knowledgeable, and 2 percent report that both are most knowledgeable but one makes the decisions.

Only about 2 percent of respondents give inconsistent answers to the two questions. Since inconsistent responses are so rare and two-thirds of respondents state that decisions are made jointly, the most knowledgeable person is a meaningful measure without incorporating additional data about who makes the major decisions.

Table 3 reports characteristics of couples, by the gender of the household CFO. Only 16 percent of couples have female CFOs. The CFO tends to be more educated, have more financial literacy, and have more fluid intelligence (as measured by the Number Series score) than his or her spouse; this is true for both male and female CFOs. These patterns are consistent with the idea that where one spouse has a comparative advantage with respect to fluid intelligence or education, s/he becomes the CFO.

\section{B. Descriptive Non-parametric Analysis: Financial Literacy by Age and Potential Confounders}

The cross-section can be used as a synthetic cohort to see if patterns of financial knowledge within couples change with age. My model predicts that women should increase their financial knowledge as they approach widowhood. Furthermore, if their husbands' cognition or health deteriorate earlier than their own, women will have greater incentive to acquire more knowledge. Because longitudinal data are not currently available, there are no measurements of baseline knowledge. To measure changes in financial knowledge in the 
synthetic cohort, I use husbands' knowledge as a baseline for women. An implicit assumption here is that the husband's current financial knowledge is an appropriate level for being the CFO; wealth is included as an additional control of the different levels of knowledge "needed" to manage the family's current finances. ${ }^{21}$

Figure 1a shows the age profile of the financial sophistication score based on the husband's age. The age profile is estimated using a lowess plot (locally weighted scatterplot smoothing), which non-parametrically estimates:

$$
\text { wife's knowledge-husband's knowledge }=f \text { (husband's age). }
$$

Men's financial sophistication follows a flat or upside-down U-shape, whereas women's scores are upward sloping with respect to their husband's age. To see if this pattern holds when women are matched to their husbands, I plot the wife-husband difference in financial literacy on Figure 1b. Within couples, the wife's score rises relative to her husband's score as he ages and his life expectancy shortens; this is also true when excluding stock questions (shown in Figure A2 in the online appendix). These patterns are not sensitive to bandwidth choice. Univariate regressions of the wife-husband difference in financial scores on the husband's life expectancy show the same negative relationship, and the slopes are statistically significant at the 10 percent and 5 percent level for sophistication and the nonstock literacy regressions, respectively (not shown).

These patterns are consistent with the notion that women acquire human capital as their husbands age. Do these empirical patterns reflect active learning on the part of the women, in anticipation of their husbands' decline in health and cognition? The age profiles in financial knowledge detailed above are also consistent with three different explanations unrelated to my theoretical model. First, the gains in women's knowledge relative to men may not actually reflect any actual gains; women's knowledge may remain constant while their husbands' cognition declines. Measuring women's financial literacy against their husband's knowledge as a baseline implicitly assumes that the husband's knowledge is, or at least is perceived by the household to be appropriate for handling the household's financial tasks. But it may be the case that the husband at one time had an appropriate level of knowledge but no longer does.

Second, older women may have been in charge of finances throughout their marriages. Third, women married to older men may differentially have additional reasons to have higher financial literacy than spouses of younger men due to wealth, larger age gaps, or second marriages. These last two explanations violate the assumptions of the synthetic cohort analysis employed here, and the results may merely reflect cohort effects rather than progression as they approach widowhood.

1 Cognitive Decline of Husbands-One might be concerned that these age profiles are generated by older men paired with younger women, such that an increase in the wife-

\footnotetext{
${ }^{21}$ Results without controlling for wealth are almost identical to those reported in this paper.
} 
husband financial knowledge gap is driven solely by a decline in the husband's ability, rather than a true increase in the woman's literacy. Figure 2 shows placebo age profiles of various other cognitive scores, plotted against the husband's age (comparable to Figure 1a). These graphs are generated by locally weighted scatterplot (lowess) smoothing. Aside from the memory score, the cognitive measures do not generally have a wife-husband gap that increases with the husband's age. The scores for husbands and wives track each other remarkably closely by the husband's age; in fact, for Calculations and Visual Matching (a measure of processing speed), men seem to gain on women at the oldest ages. Furthermore, the Number Series scores, which have been shown to be strong predictors of financial literacy and wealth (McArdle, Smith, and Willis 2011), have parallel profiles for both men and women. ${ }^{22}$ These patterns suggest that the age profile of financial literacy scores does not merely track underlying patterns of cognitive decline of husbands and wives in these six measures of cognition. Because the memory score is the exception, all regressions will include controls for the husbands' and wives' Auditory Memory score, as well as additional measures that typically exhibit declines with age. Still, for women's gains in financial literacy relative to their husbands to be attributable to learning, the cognitive decline of husbands must be fully captured by the controls for memory, fluid intelligence, and processing speed. For further evidence of learning that does not require this assumption, I also conduct robustness checks in Section V.D.2 using a panel dataset to confirm that women also gain financial knowledge in absolute terms, and that these gains are not limited to those with the oldest husbands.

2 Cohort Effects-Using the cross-section as a synthetic cohort assumes that the experiences of individuals over the age distribution of the cross-section reflect the experiences of individuals as they age through each successive cohort, as if I had observed a single cohort longitudinally. ${ }^{23}$ An alternative hypothesis consistent with my results is that older women have been household CFOs throughout the marriage, while younger women have not. This would cause the synthetic cohort to produce spurious support for the model's predictions.

However, social changes across cohorts suggest otherwise; historical marriage and divorce patterns are likely to bias the data against my model's predictions. Women in younger cohorts are likely to have married at an older age, as seen in the Current Population Survey and Census data in Figure 3a. ${ }^{24}$ Although the median age of women married before 1949 (the 5th percentile in my data of the year of first marriage) was slightly older, there was subsequently an upward trend over time. Therefore, the younger women in my sample have had greater incentive to gain financial knowledge prior to marriage. In addition, if the dispersion of power within a couple is greater when the spousal age gap is larger, we may not expect the younger spouses of the older men to have as much control over finances.

\footnotetext{
${ }^{22}$ In univariate regressions of the wife-husband gap on the husband's age, the slope coefficients are only positive and statistically significant for memory.

${ }^{23}$ One common use of the synthetic cohort is the computation of life table life expectancies, which are expected to be downward biased because younger cohorts will have the benefit of medical advances not available to those who are already elderly.

${ }^{24}$ This figure was constructed using Table MS-2 posted online by the U.S. Census Bureau at https://www.census.gov/hhes/families/ data/marital.html.
} 
Younger couples are likely to be more "egalitarian" than older couples, and therefore older women might be less likely to be the CFO.

The prospect of divorce, which has changed considerably over time, may also lead women to learn about finances earlier in life. Historical divorce rates in the United States are shown in Figure $3 b^{25}$ Although the rates were slightly higher in the mid-1940s than in the 1950s, divorce rates climbed rapidly through the 1960s and 70s. Divorce rates remained high through the 80s and declined only more recently. The sharp increase in divorce rates would create incentives for the younger women in my sample to insure themselves by acquiring more knowledge earlier in adulthood. These patterns, in addition to changing norms due to the rise of feminism, would create greater incentives for younger women (relative to older women) to learn early and/or become CFOs in the household. All of these cohort effects should produce downward bias on any estimates of the effects of time to widowhood on financial knowledge.

Another possibility is that husbands' age is still correlated with other demographic and economic factors that increase the incentive for women to gain financial literacy, apart from the aging and widowhood incentive. Age profiles of some of these factors are shown in Figure A3 in the online appendix. If the wives of older husbands come from second marriages (perhaps through widowhood or divorce), then these women might enter these marriages with more financial knowledge from their past experience with independent financial decision-making. In the CogEcon sample, however, in general the older the husband, the more likely the woman is on her first marriage (and the less likely she was previously divorced) and the longer the duration of the current marriage. Older men are married to older women, but the age gap does increase somewhat with the husband's age. Still, perhaps older men are wealthier, and women with high wealth may have greater incentives to learn more about finances due to the potential of greater return (or losses due to mismanagement). In the CogEcon sample, wealth follows the same hump-shaped life-cycle trajectory as expected, and the oldest men are no wealthier than those in their fifties. The correlation between husband's age and wealth (whether measured in dollar values or deciles) is 0.08 ; the correlation between wealth and wife-husband age gap is -0.10 . These low correlations suggest that wives of older men do not face greater incentives to acquire financial literacy due to greater wealth in the analysis sample.

In sum, cohort effects stemming from marriage and divorce shifts in the population are unlikely to drive my results. Furthermore, women married to the older men in the sample do not appear to have reasons for differentially higher past experience with independent financial decision-making, or differentially greater wealth to potentially manage, than women married to younger men. Still, as a robustness check, I will analyze some proxies for financial literacy using panel data in Section V.D.2.

\footnotetext{
${ }^{25}$ Statistics prior to 1950 are drawn from Table 57 of U.S. Bureau of the Census (1954); those from 1950 onward are from Table 70 of U.S. Census Bureau (2004).
} 


\section{Regression Analysis}

Using matched data on husbands and wives, I estimate the effect of expected time to widowhood and expected length of widowhood on women's financial knowledge (derivations in the online appendix). Table 2 reports summary statistics of the financial knowledge and widowhood variables used in the analysis. Women have on average -0.37 standard deviations less financial sophistication than their husbands, and -0.31 less for nonstock literacy questions alone. In this sample, the average expected time to widowhood (conditional on the woman outliving the man) is 15 years, with a mean expected duration of widowhood of 13 years. $^{26}$

Table 4 presents estimation results for the following equation:

$d($ financial knowledge $)=\gamma_{1}($ expected time to widowhood $)+\gamma_{2}($ expected duration of widowhood $)+X \beta+\varepsilon$

where $d(x)$ designates the wife-husband difference in $x$.

The first column of Table 4 estimates the equation with no covariates, while the second includes the usual education and health controls. Column (3) adds measures of fluid intelligence (Number Series and Matrix Reasoning), processing speed (Visual Matching), and working memory (Auditory Memory) for both husband and wife, as well the wealth decile. Including these cognition variables increases the magnitude and precision of the estimated coefficient on the time to widowhood. A one-year reduction in the expected time to widowhood is associated with a statistically significant 0.04 standard deviation increase in the wife-husband difference in normalized financial sophistication, which is about 11 percent of the mean difference. This result arises even when controlling for four different cognitive measures that decline markedly with age.

Several of the questions in the financial sophistication battery measure concepts that may not be relevant to members of households who do not participate in the stock market. I construct a second financial literacy score excluding stock-related questions and standardize them over all respondents. Columns (4) through (6) of Table 4 repeat the analysis with this smaller set of more basic literacy questions. The coefficient on the time to widowhood is much larger in magnitude; in the specification with full cognition controls in the last column, this coefficient increases 15 percent to -0.047 from -0.043 in column (1).

This suggests that women make the greatest gains on basic forms of literacy. The Number Series score is a strong predictor of financial knowledge, and since this is a measure of fluid intelligence, having a higher Number Series score can be interpreted as lowering the

\footnotetext{
${ }^{26}$ These figures use life table aggregate statistics from individuals of all marital statuses. This assumes that the mortality of husbands and wives are uncorrelated, and that any marriage treatment effect on life expectancy does not differ in magnitude between husbands and wives. If one does not condition on the woman outliving the husband, life tables also indicate an average life expectancy of almost 20 years for the husbands, with wife-husband difference in life expectancies of over four years. All analyses using these unconditional measures yield similar results.
} 
woman's marginal cost of acquiring knowledge. A one standard deviation increase in the wife's Number Series score is associated with a 0.37 standard deviation increase in her financial sophistication relative to her husband. Coefficients on the control variables are generally as expected: the lower the education and health levels of the husbands, the greater the woman's financial knowledge. Likewise, the greater are a woman's levels of health or education, the greater her financial knowledge, and these effects are smaller in magnitude than those of her husband's levels.

Even after including controls for working memory, processing speed, and an additional measure of fluid intelligence, all of which decline strongly with age and therefore help control for the husband's cognitive decline, I still find a statistically significant effect of time to widowhood on financial literacy. The magnitude of the effect is large; if all women acquired financial literacy at the estimated 0.04 standard deviation per year, almost 80 percent of women in the sample would fully catch up with their husband's current level of financial literacy before the expected onset of widowhood. The coefficients on the expected duration of widowhood are positive - the longer the length of widowhood, the more financial literacy the woman has relative to her husband - but are not statistically significant. These results are consistent with the fact that the model predicts the effect of the marginal year closer widowhood should be much larger than the marginal year during widowhood.

\section{Robustness Checks and Extensions}

1 Falsification Tests-As a robustness check, I run false regressions of equation (5) by replacing the difference in financial sophistication scores on the left hand side with differences in cognition scores. Table 5 reports the results for the six cognition scores detailed in Section IV.C. Because the left hand side variables are all wife-husband differences in standardized scores, the coefficients are directly comparable to each other. The columns are ordered from most highly correlated to least correlated to financial literacy. All of the falsification regressions have coefficients on the time to widowhood that are smaller in magnitude than the same coefficient in the financial literacy regression; all but two are statistically indistinguishable from zero. The measure with largest negative coefficient on time to widowhood, Matrix Reasoning, is not highly correlated with financial literacy; furthermore, the full regressions in Table 4 control for this measure of fluid intelligence. This suggests that the estimated effect of time to widowhood on financial literacy is not a spurious relationship solely attributable to the cognitive decline of men. ${ }^{27}$

\section{Longitudinal Analysis Using Financial Knowledge Proxies on the HRS-For} additional evidence that the effects I find in the CogEcon sample are not attributable to the cognitive decline of husbands, I turn to panel data in the Health and Retirement Study (HRS) and analyze proxies for financial literacy. This longitudinal dataset allows me to track outcomes for a given individual over time and therefore preclude the need for an external baseline, albeit without the rich set of cognition measures or the direct measure of financial

${ }^{27}$ This interpretation of the coefficient on time to widowhood assumes that the cognitive decline of men is fully captured by the controls for two measures of fluid intelligence, working memory, and processing speed, which are typically the forms of cognition that decline most markedly with age. 
literacy from the main analyses. Respondents' beliefs about stock market returns, as well as the extent to which they follow the market, complement financial literacy as measures of general knowledge because they have direct bearing on financial planning, stock market participation, and investment behavior. First, I use the question, "How closely do you follow the stock market?" coded as one if the respondent answers "very closely" or "somewhat" and zero otherwise. In addition, the HRS asks about respondents' probabilistic expectations of future stock market performance: "By next year at this time, what is the percent chance that mutual fund shares invested in blue chip stocks like those in the Dow Jones Industrial Average will be worth more than they are today?" Answering this question, instead of refusing or stating "don't know," could be a rough proxy for financial literacy, or at least comfort with or willingness to answer economic questions. I construct a variable that takes the value of one if the respondent provides an answer to this question, and zero if she refuses or does not know. Third, I compare responses to the Dow Jones expectations question to actual realizations of the Dow Jones Industrial Average (DJIA) 12 months after the interview date. If a respondent answered at least 50 percent and the DJIA indeed rose, or if she answered at most 50 percent and the DJIA fell, the variable is coded as one, and zero otherwise.

These variables are available starting in 2002, and I estimate a set of regressions with individual-level fixed effects using data on married women through 2010. Individual-level fixed effects regressions allow for an analysis of within-woman changes in financial literacy proxies, and are therefore free of confounders from time-invariant individual-level factors like birth cohort or education of either spouse. This strategy also precludes the need for an external baseline for the outcome, like husband's financial literacy used in the main analysis.

These fixed-effects regressions control for time-varying measures of the wealth decile, husbands' and wives' self-reported health (identical to the CogEcon measure) and 27-point composite cognition scores, and year dummies. ${ }^{28}$ Results, as well as means of the dependent variables, are reported in the first three columns of Table 6 . The negative and precisely measured coefficients for all three regressions on the expected time to widowhood provide longitudinal evidence that the closer a woman is to widowhood, the higher her measures of financial sophistication. ${ }^{29}, 30$

Given that cognitive decline accelerates with age, and the effects found in the main crosssectional analysis could still be partially driven by cognitive decline of men not captured by my control variables, columns (4) through (6) report estimates that interact each widowhood variable with an indicator that the husband is over 60 . For following the stock market and

\footnotetext{
${ }^{28}$ More detailed cognition measures like those found in CogEcon are not available longitudinally for the entire HRS sample. See Hsu and Willis (2013) for more details on this score.

${ }^{29}$ The HRS also designates a financial respondent, who is in theory the CFO of the family. Hsu and Willis (2013) analyze how changes in the cognitive status of the family's original financial respondent influences the likelihood that the spouse becomes the financial respondent, regardless of gender. The authors find that as the original CFO's cognition declines, the cognitively intact spouse eventually becomes the new financial respondent, often well after difficulties handling money have already emerged. This switch occurs much earlier for couples who have individually-managed retirement accounts than for those who only passively receive retirement income, which provides additional evidence that the division of labor evolves over the life cycle and responds to incentives from spousal characteristics and wealth composition.

${ }^{30}$ Cross-sectional analysis using similar variables on CogEcon are reported in the online appendix, although the categorical nature of these variables makes the synthetic cohort approach less compelling. Still, the coefficients on time to widowhood are again negative, albeit imprecisely measured.
} 
answering the DJIA expectations question, the effect of time to widowhood accelerates or continues after the husband is 60 . For the accuracy of the expectations question, the effect of time to widowhood is more modest when the husband is over 60 , but continues to be negative. These results are consistent with the idea that women increase financial literacy as they approach widowhood, whether their husbands are relatively young or old. ${ }^{31}$

\section{Probabilistic Survival Measures}

As a third robustness check, I repeat the analysis of the CogEcon financial literacy outcome using widowhood probabilities computed from ten-year probabilistic survival measures. Instead of using life table widowhood measures that mask individual variation in actual survival expectations, here I use individual-specific survival measures drawn from subjective probabilities elicited on the survey and objective probabilities predicted using individual characteristics. The results, detailed in the online appendix, are qualitatively similar to the main analysis, again showing a negative effect of widowhood probabilities on women's financial literacy.

\section{Heterogeneity in Effects}

In this section, I explore possible heterogeneity in the CogEcon sample by repeating the estimation on particular subsamples of the data that face varying incentives to acquire financial literacy as they approach widowhood. First, the analysis above assumes that the husband has been the CFO of the family. However, women who are already the financial specialist in the family do not have face the same incentives of widowhood to acquire additional financial literacy. Columns (1) and (2) of Table 7 report estimates of equation (5) on the subsample where the woman reports that she is the CFO, and she is not the CFO, respectively. ${ }^{32}$ For women who are not currently CFOs, time to widowhood has an even larger and more precisely measured effect on women's financial literacy, whereas where if she is the CFO, the effect is positive (albeit imprecisely measured). These results are consistent with the idea that when husbands manage finances in the division of labor, women have larger incentives to gain financial literacy relative to women who are already CFOs.

Next, I split the sample by wealth; couples in the upper five deciles of wealth are included in column (3), and those with wealth in the lower five deciles are in column (4). ${ }^{33}$ Those with higher wealth are more responsive to time to widowhood than those with less wealth, consistent with the idea women with more assets to manage may have more incentive to learn than those with less wealth. Similarly, the final two columns of Table 7 reports results for couples with and without stock holdings, respectively. Here, the two coefficients on time to widowhood are similar, though the effect is precisely measured only for the stock-owning subsample.

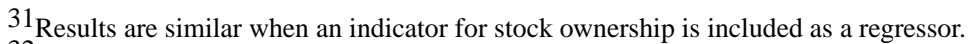

32 For these analyses, if a woman selects "both of us equally" to the CFO question, she is included in the "wife is not CFO" group.

${ }^{33}$ The subsamples are uneven because the wealth deciles were estimated using all CogEcon households, including singletons, who tend to have lower wealth than couples.
} 


\section{Conclusion}

Empirical studies on financial literacy have generally shown that women have less financial knowledge than men (Fonseca et al. 2012; Lusardi and Mitchell 2008; Kotlikoff and Bernheim 2001). One possible explanation for this gender gap is that it reflects the household division of labor. Unequal life expectancies of household members imply that a division of labor that emerges when the couple forms will eventually change when the longer-living spouse takes over the responsibilities held by the shorter-living spouse. Household financial management is a task that is frequently the responsibility of the husband, who generally has a shorter life expectancy than the wife. Because the benefits of financial knowledge for women are not realized until she is a widow, the theoretical model predicts that a woman has an incentive to delay the acquisition of financial knowledge until later in life. Conversely, because knowledge cannot be acquired instantaneously, she also has an incentive to begin her acquisition of financial knowledge well before widowhood so that she will be equipped with the knowledge needed to manage her wealth when her husband dies.

Using matched data on wives and husbands, I show that women do indeed increase their financial knowledge on a number of dimensions as their husbands age. Women acquire financial literacy at a rate of 0.04 standard deviations per year, assuming the cognitive decline of men is captured by the rich set of controls for cognition that typically decline with age. At this rate, about 80 percent of the women in the sample would catch up with their husbands in financial literacy before the expected onset of widowhood. In addition, women have increased self-rated financial skills and follow the stock market more closely as widowhood becomes more imminent. Because cohort effects related to age at first marriage and divorce probabilities work against my finding a result, my estimates understate the actual effects. Furthermore, I find statistically significant effects of the time to widowhood in spite of the measurement error associated with using population-average life table calculations.

However, I do not find a statistically significant effect of the expected length of widowhood on women's financial knowledge. This may not be surprising given that the model predicts a much larger effect of time to widowhood than the length of widowhood. Assuming a discount factor of 0.97 and no depreciation, the effect of time to widowhood is predicted to be on average 50 percent larger than the duration's effect, with a larger gap if human capital depreciates. Furthermore, while the model does not specify the functional form of the returns to financial knowledge, the financial decisions faced by widows may be less complex than the planning decisions made earlier in the life cycle. If this is the case, then the marginal returns to financial knowledge may decline sharply after a certain threshold.

Women may aim to reach a level of financial knowledge at widowhood sufficient to manage their decumulation, but not necessarily so much as to make complex investment decisions. The financial literacy outcome uses the husband's literacy as a baseline in order to identify effects from a synthetic cohort formed by a cross-section. My results show that older women do indeed plan for the future by strategically investing in financial knowledge as widowhood becomes more imminent. The results support the idea that the poor economic outcomes 
associated with widowhood may reflect insufficient preparation due to an unexpectedly early onset of widowhood. In addition, poor outcomes may also reflect low levels of husbands' financial knowledge; in this case, merely catching up with their husbands (as many women would, according to my estimates) may not fully equip women with the tools needed to manage their finances alone.

The model generates implications for other aspects of the life cycle. First, the time profile of financial literacy acquisition should change at widowhood. Second, we should expect differences in the financial literacy profiles and even financial outcomes of women who go through anticipated versus unanticipated widowhood. While this paper shows that women generally do respond rationally to the prospect of widowhood, those whose husbands die unexpectedly may need to increase their financial human capital investments to "catch up" with their planned profile, or may suffer from the poorer economic outcomes associated with widowhood more generally. Lastly, annuitization might be a substitute for acquiring the sophistication required to actively manage ones' finances in retirement and widowhood. The analysis can be applied not only to financial literacy but also to any other task specialized in by a spouse. In addition, the model can also be generalized to other questions related to the length of time a person can depend on a spouse to continue specializing. Korniotis and Kumar (2011) find that older investors exhibit greater investment knowledge, but that these effects are offset by the adverse effects of cognitive aging which further incentivizes early planning for women who may want to prepare not only for widowhood but also for the cognitive decline of their husbands. Future work will specifically consider the effects of cognitive decline. Since the model shows declining incentives to invest after widowhood, it sheds some light on the stylized fact that widows have very low levels of financial knowledge. Furthermore, financial literacy profiles should differ between women whose timing of widowhood is anticipated and those who become widows unexpectedly early, due to an accident, for example. The model can also be applied more generally to the expected duration of the union rather than the expected timing of widowhood, so the same implications can be drawn for women facing varying probabilities of divorce. One extension not yet considered is the availability of an outside option for dealing with the shorter-living spouse's tasks. Instead of learning to manage her own wealth, she can have a third person, whether an adult child or a financial planner, manage her finances on her behalf. Indeed, the third-person option may be one reason why women react less strongly to a longer expected duration of widowhood.

\section{Acknowledgments}

The author thanks Robert Willis, Jeff Smith, Matthew Shapiro, Miles Kimball, Raj Arunachalam, Shanthi Ramnath, Brian Kovak, Brooke Helppie McFall, Marta Murray-Close, Pamela Giustinelli, Michael Gideon, and anonymous referees for helpful comments and suggestions. The author also gratefully acknowledges support received at the University of Michigan from the National Institute on Aging grant 2P01AG026571 and fellowship support from the Networks Financial Institute at Indiana State University. The analysis and conclusions set forth are those of the author and do not indicate concurrence by other members of the research staff or the Board of Governors. The datasets and supplementary figures rely on publicly available data. The author is happy to provide guidance about obtaining the data and replicating the analyses in this paper. 


\section{References}

Agarwal, Sumit, Driscoll, John C., Gabaix, Xavier, Laibson, David I. The Age of Reason: Financial Decisions over the Life-Cycle with Implications for Regulation. Brookings Papers on Economic Activity. 2009; 2009(2):51-117.

Arias, Elizabeth. United States Life Tables, 2004. National Vital Statistics Reports. 2007; 56(9):1-39.

Azzi, Corry, Ehrenberg, Ronald. Household Allocation of Time and Church Attendance. Journal of Political Economy. 1975; 83(1):27-56.

Backman, Lars, Small, Brent J., Wahlin, Ake. Aging and Memory: Cognitive and Biological Perspectives. In: Birren, James E., Warner Schaie, K., editors. Handbook of the Psychology of Aging. San Diego: Academic Press; 2001. p. 349-377.

Becker, Gary S. Human Capital, Effort, and the Sexual Division of Labor. Journal of Labor Economics. 1985; 3(1):S33-S58.

Ben-Porath, Yoram. The Production of Human Capital and the Life Cycle of Earnings. Journal of Political Economy. 1967; 75(4):352-365.

Bernheim, B Douglas. Financial Illiteracy, Education and Retirement Saving. In: Mitchell, Olivia S., Schieber, Sylvester J., editors. Living with Defined Contribution Pensions: Remaking Responsibility for Retirement. Philadelphia: University of Pennsylvania Press; 1998. p. 38-68.

Bernheim, B Douglas, Garrett, Daniel M., Maki, Dean M. Education and saving: The long-term effects of high school financial curriculum mandates. Journal of Public Economics. 2001; 80(3):435-465.

Carlin, Bruce Ian, Robinson, David T. What Does Financial Literacy Training Teach Us? Journal of Economic Education. 2012; 43(3):235-247.

Cattell, Raymond B. Some Theoretical Issues in Adult Intelligence Testing. (Abstract). Psychological Bulletin. 1941; 38:592.

Chen, Haiyang, Volpe, Ronald P. Gender Differences in Personal Financial Literacy Among College Students. Financial Services Review. 2002; 11(3):289-307.

Cognition and Aging in the USA Study. Waves 1 and 2 datasets. Produced by the University of Michigan for the University of Southern California with funding from the National Institute on Aging. 2011. (grant number NIA R 37 AG007137, PI: McArdle)

Cognitive Economics Study. Produced and distributed by the University of Michigan with funding from the National Institute on Aging. Ann Arbor, MI: 2012. CogEcon Public Core Release (Version 1.0) public use dataset. (grant number NIA P01 AG026571)

Cole, Shawn A., Paulson, Anna, Shastry, Gauri Kartini. Smart Money? The Effect of Education on Financial Outcomes. Review of Financial Studies. 2014; 27(7):2022-2051.

Delavande, Adeline, Rohwedder, Susann, Willis, Robert J. Michigan Retirement Research Center Working Paper WP 2008-190. 2008. Preparation for Retirement, Financial Literacy and Cognitive Resources.

Fonseca, Raquel, Mullen, Kathleen J., Zamarro, Gema, Zissimopoulos, Julie. What Explains the Gender Gap in Financial Literacy? The Role of Household Decision Making. Journal of Consumer Affairs. 2012; 46(1):90-106. [PubMed: 23049140]

Gourinchas, Pierre-Olivier, Parker, Jonathan A. Consumption over the Life Cycle. Econometrica. 2002; 70(1):47-89.

Health and Retirement Study. Produced and distributed by the University of Michigan with funding from the National Institute on Aging. Ann Arbor, MI: 2014. 1998, 2000, 2002, 2004, 2006, 2008 , and 2010 HRS Core public use datasets. (grant number NIA U01AG009740)

Hilgert, Marianne A., Hogarth, Jeanne M., Beverly, Sondra G. Household Financial Management: The Connection between Knowledge and Behavior. Federal Reserve Bulletin. 2003; 2003(July):309_ 322.

Horn, John L. PhD dissertation. University of Illinois; 1965. Fluid and crystallized intelligence: A factor analytic and developmental study of the structure among primary mental abilities.

Horn, John L., Cattell, Raymond B. Refinement and test of the theory of fluid and crystallized general intelligences. Journal of Educational Psychology. 1966; 57(5):253-270. [PubMed: 5918295] 
Horn, John L., Cattell, Raymond B. Age differences in fluid and crystallized intelligence. Acta Psychologica. 1967; 26(2):107-129. [PubMed: 6037305]

Hsu, Joanne W., Willis, Robert. Dementia Risk and Financial Decision Making by Older Households: The Impact of Information. Journal of Human Capital. 2013; 7(4):340-377.

Johnson, William R., Skinner, Jonathan. Labor Supply and Marital Separation. American Economic Review. 1986; 76(3):455-469.

Korniotis, George M., Kumar, Alok. Do Older Investors Make Better Investment Decisions? Review of Economics and Statistics. 2011; 93(1):244-265.

Kotlikoff, Laurence J., Douglas Bernheim, B. Household Financial Planning and Financial Literacy. In: Kotlikoff, Laurence J., editor. Essays on Saving, Bequests, Altruism, and Life-Cycle Planning. Cambridge: The MIT Press; 2001. p. 427-478.

Lusardi, Annamaria, Mitchell, Olivia S. Baby Boomer retirement security: The roles of planning, financial literacy, and housing wealth. Journal of Monetary Economics. 2007; 54(1):205-224.

Lusardi, Annamaria, Mitchell, Olivia S. Planning and Financial Literacy: How Do Women Fare? American Economic Review. 2008; 98(2):413-417.

Lusardi, Annamaria, Mitchell, Olivia S. National Bureau of Economic Research Working Paper 15350. 2009. How Ordinary Consumers Make Complex Economic Decisions: Financial Literacy and Retirement Readiness.

Lusardi, Annamaria, Mitchell, Olivia S. Financial Literacy and Planning: Implications for Retirement Wellbeing. In: Lusardi, Annamaria, Mitchell, Olivia, editors. Financial Literacy: Implications for Retirement Security and the Financial Marketplace. New York: Oxford University Press; 2011. p. 17-39.

Lusardi, Annamaria, Tufano, Peter. National Bureau of Economic Research Working Paper 14808. 2009a. Debt Literacy, Financial Experiences, and Overindebtedness.

Lusardi, Annamaria, Tufano, Peter. Teach Workers about the Perils of Debt. Harvard Business Review. 2009b:22-24.

Lusardi, Annamaria, Mitchell, Olivia S., Curto, Vilsa. National Bureau of Economic Research Working Paper 15469. 2009. Financial Literacy and Financial Sophistication Among Older Americans.

Lusardi, Annamaria, Mitchell, Olivia S., Curto, Vilsa. Financial Literacy among the Young. Journal of Consumer Affairs. 2010; 44(2):358-380.

McArdle, John J., Ferrer-Caja, Emilio, Hamagami, Fumiaki, Woodcock, Richard W. Comparative Longitudinal Structural Analyses of the Growth and Decline of Multiple Intellectual Abilities Over the Life Span. Developmental Psychology. 2002; 38(1):115-142. [PubMed: 11806695]

McArdle, John J., Hamagami, Fumiaki, Meredith, William, Bradway, Katherine P. Modeling the dynamic hypotheses of Gf-Gc theory using longitudinal life-span data. Learning and Individual Differences. 2000; 12(1):53-79.

McArdle, John J., Fisher, Gwenith G., Kadlec, Kelly M. Latent variable analyses of age trends of cognition in the Health and Retirement Study, 1992-2004. Psychology and Aging. 2007; 22(3): 525-545. [PubMed: 17874952]

McArdle, John J., Smith, James P., Willis, Robert J. Cognition and Economic Outcomes in the Health and Retirement Survey. In: Wise, David A., editor. Explorations in the Economics of Aging. Chicago: University of Chicago Press; 2011. p. 209-236.

Mincer, Jacob, Polachek, Solomon. Family Investments in Human Capital: Earnings of Women. Journal of Political Economy. 1974; 82(2):S76-S108.

RAND HRS Data. Produced by the RAND Center for the Study of Aging, with funding from the National Institute on Aging and the Social Security Administration. Santa Monica, CA: 2014. Version N.

Salganicoff, Alina, Zoe Beckerman, J., Wyn, Roberta, Ojeda, Victoria D. Women's Health in the United States: Health Coverage and Access to Care. The Henry J. Kaiser Family Foundation; 2002. http://www.kff.org/womenshealth/20020507a-index.cfm

Salganicoff, Alina, Ranji, Usha R., Wyn, Roberta. Women and Health Care: A National Profile. The Henry J. Kaiser Family Foundation; 2005. http://www.kff.org/womenshealth/7336.cfm 
Salthouse, Timothy A. Aging and measures of processing speed. Biological Psychology. 2000; 54(13):35-54. [PubMed: 11035219]

Schoen, Robert, Standish, Nicola. The Retrenchment of Marriage: Results from Marital Status Life Tables for the United States, 1995. Population and Development Review. 2001; 27(3):553-563.

Stratton, Leslie S. The Degree of Intrahousehold Specialization in Housework and How Specialization Varies Across Couple Households. Paper presented at the annual meeting of the Society of Labor Economists; 2005.

U.S. Bureau of the Census. Statistical Abstract of the United States: 1954. 75. Washington, D.C: 1954.

U.S. Census Bureau. Statistical Abstract of the United States: 2004-2005. 124. Washington, D.C: 2004.

U.S. Census Bureau. Statistical Abstract of the United States: 2011. 130. Washington, D.C: 2010.

Van Rooij, Maarten, Lusardi, Annamaria, Alessie, Rob. Financial literacy and stock market participation. Journal of Financial Economics. 2011; 101(2):449-472.

Verhaeghen P, Salthouse TA. Meta-Analyses of Age-Cognition Relations in Adulthood: Estimates of Linear and Nonlinear Age Effects and Structural Models. Psychological Bulletin. 1997; 122(3): 231-249. [PubMed: 9354147] 


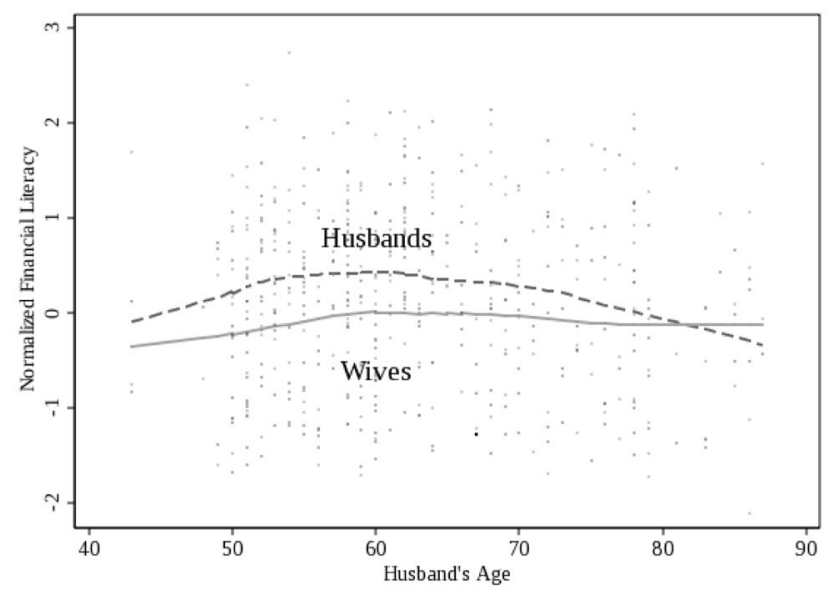

(a) Financial Literacy of Couples

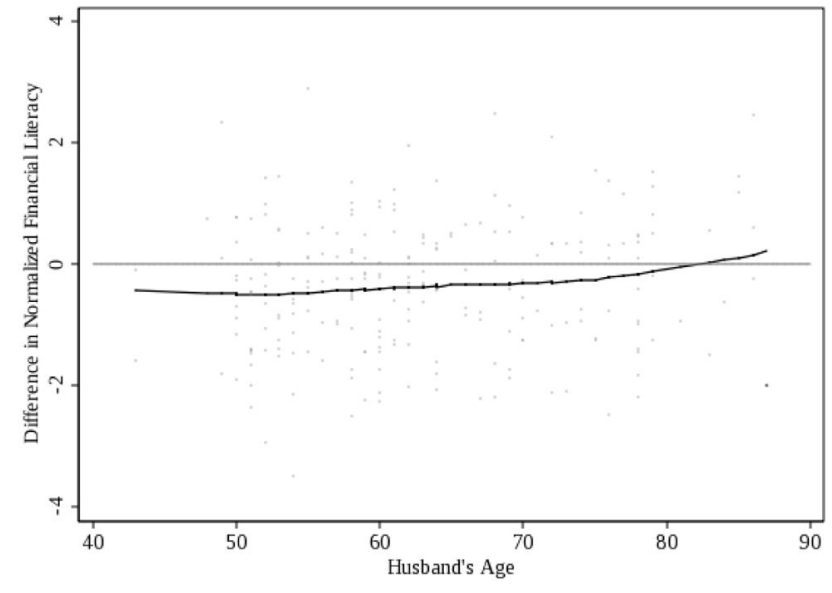

(b) Wife-Husband Difference in Financial Literacy

Figure 1. Financial Literacy and Husband's Age Data sources: CogEcon and CogUSA. 

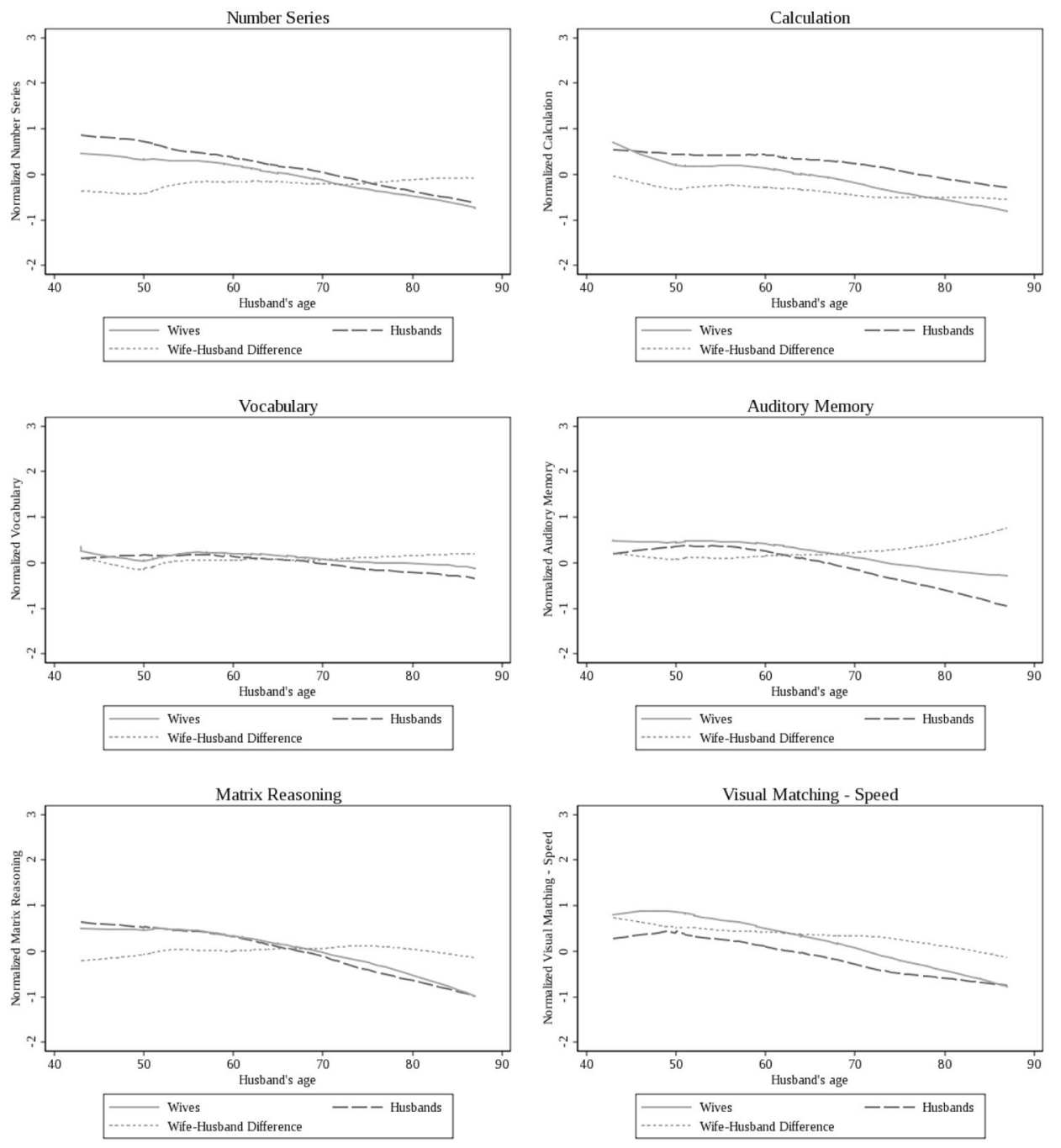

Figure 2. Cognitive Measures and Husband's Age Notes: All scores are standardized using all CogUSA respondents, pooling together men and women. Unlike financial literacy, women's cognition scores do not systematically gain on their husband's scores. The cognition variables are detailed in Section IV.C.

Data source: CogUSA. 


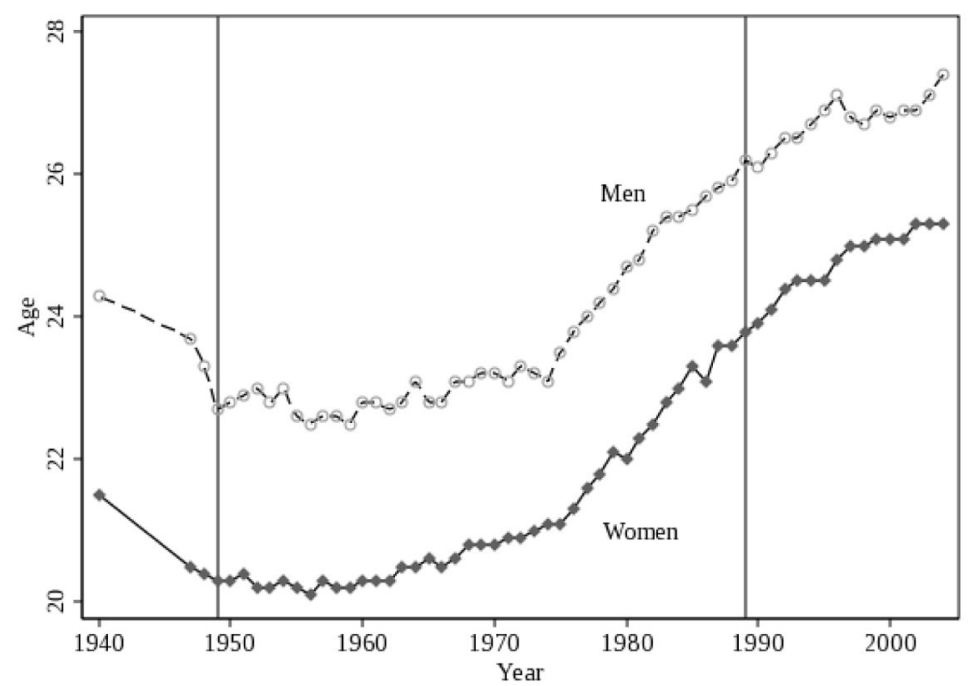

(a) Median Age at First Marriage

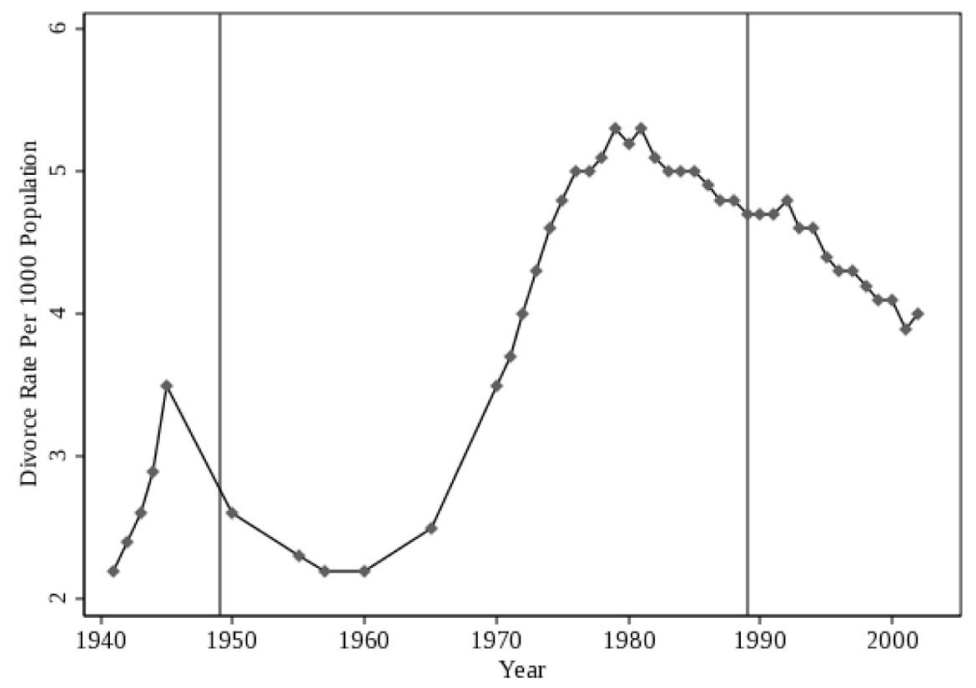

(b) Divorce Rates

Figure 3. Historical Demographic Patterns in the United States

Notes: Vertical lines indicate the $5^{\text {th }}$ and $95^{\text {th }}$ percentile of year of first marriage among women in the analysis sample. Younger women face greater incentives than older women to acquire financial literacy early in life.

Data sources: CPS, Decennial Census, and Statistical Abstract of the United States. 

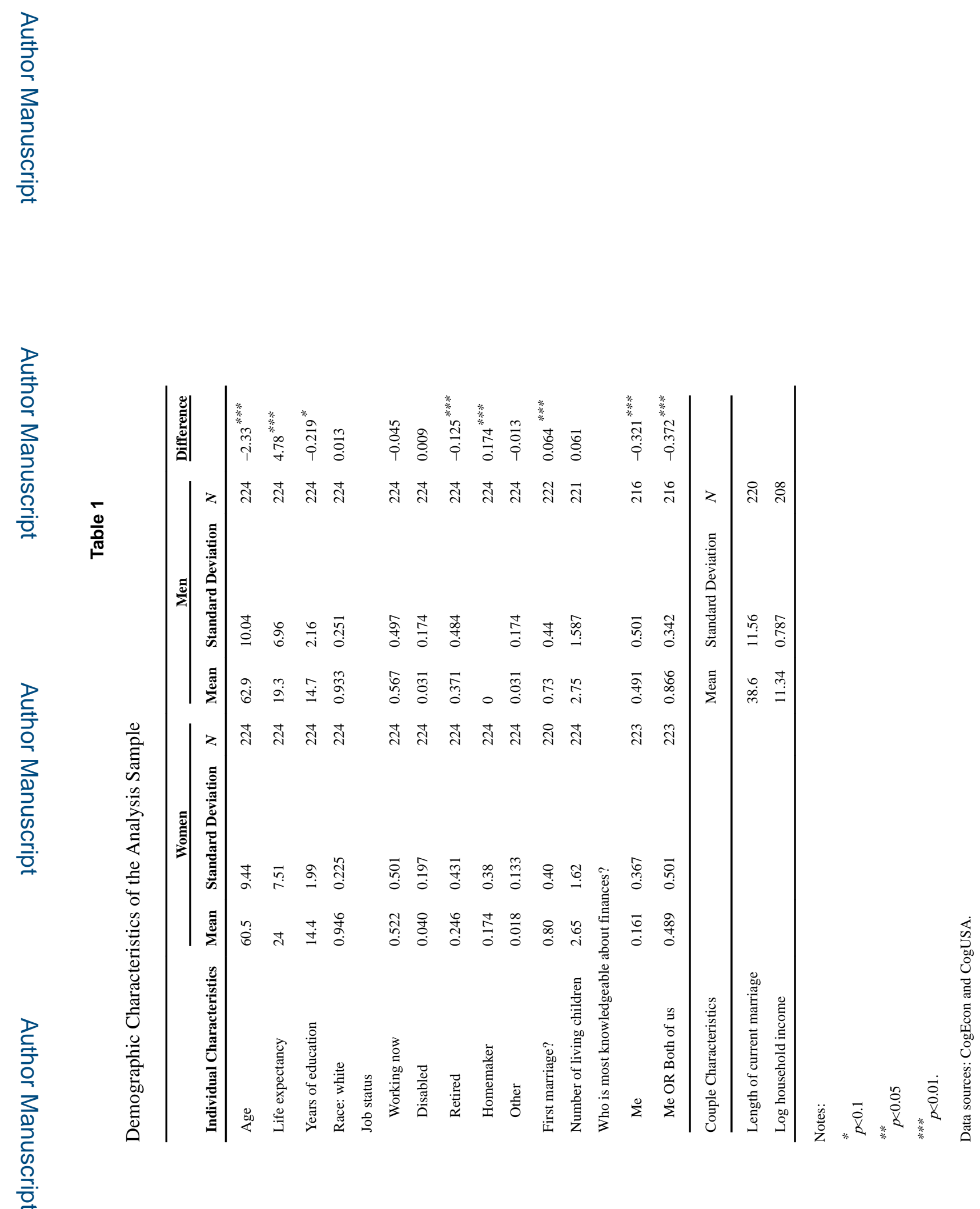

J Hum Resour: Author manuscript; available in PMC 2017 January 30. 
Table 2

Summary of Regression Variables

\begin{tabular}{llll}
\hline Variable & Mean & Standard Deviation & $N$ \\
\hline Outcomes & & & \\
Wife-husband diff. in normalized financial literacy & -0.367 & 1.10 & 224 \\
Wife-husband diff. in fin. literacy (no stock questions) & -0.309 & 1.25 & 224 \\
\hline Key explanatory variables & & & \\
Expected time to widowhood (years) & 14.6 & 5.86 & 224 \\
Expected length of widowhood (years) & 13.3 & 2.82 & 224 \\
\hline Other regressors & & & \\
Woman's years of education & 14.4 & 1.99 & 224 \\
Husband's years of education & 14.6 & 2.16 & 224 \\
Woman's self-rated health (5 point scale) & 3.73 & 0.961 & 224 \\
Husband's self-rated health (5 point scale) & 3.63 & 1.00 & 224 \\
Wealth decile & 6.39 & 2.69 & 224 \\
Woman's Number Series & 0.15 & 0.859 & 224 \\
Husband's Number Series & 0.346 & 0.882 & 222 \\
Woman's Visual Matching & 0.442 & 0.860 & 224 \\
Husband's Visual Matching & 0.070 & 0.806 & 217 \\
Woman's Auditory Working Memory & 0.357 & 0.646 & 223 \\
Husband's Auditory Working Memory & 0.102 & 0.944 \\
Woman's Matrix Reasoning & 0.248 & 0.851 & 223 \\
Husband's Matrix Reasoning & 0.220 & 0.837 & \\
\hline
\end{tabular}

Data sources: CogEcon and CogUSA. 


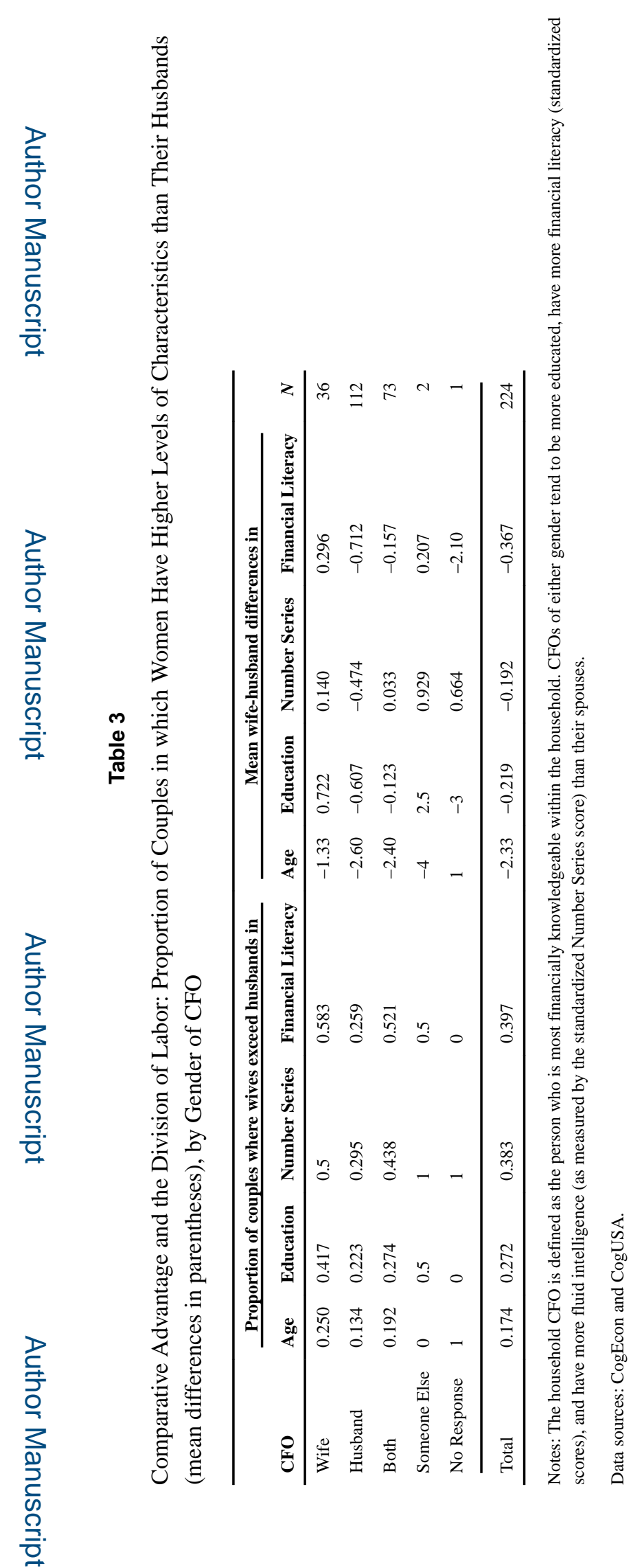

J Hum Resour: Author manuscript; available in PMC 2017 January 30. 


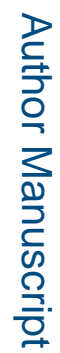

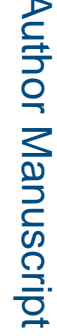

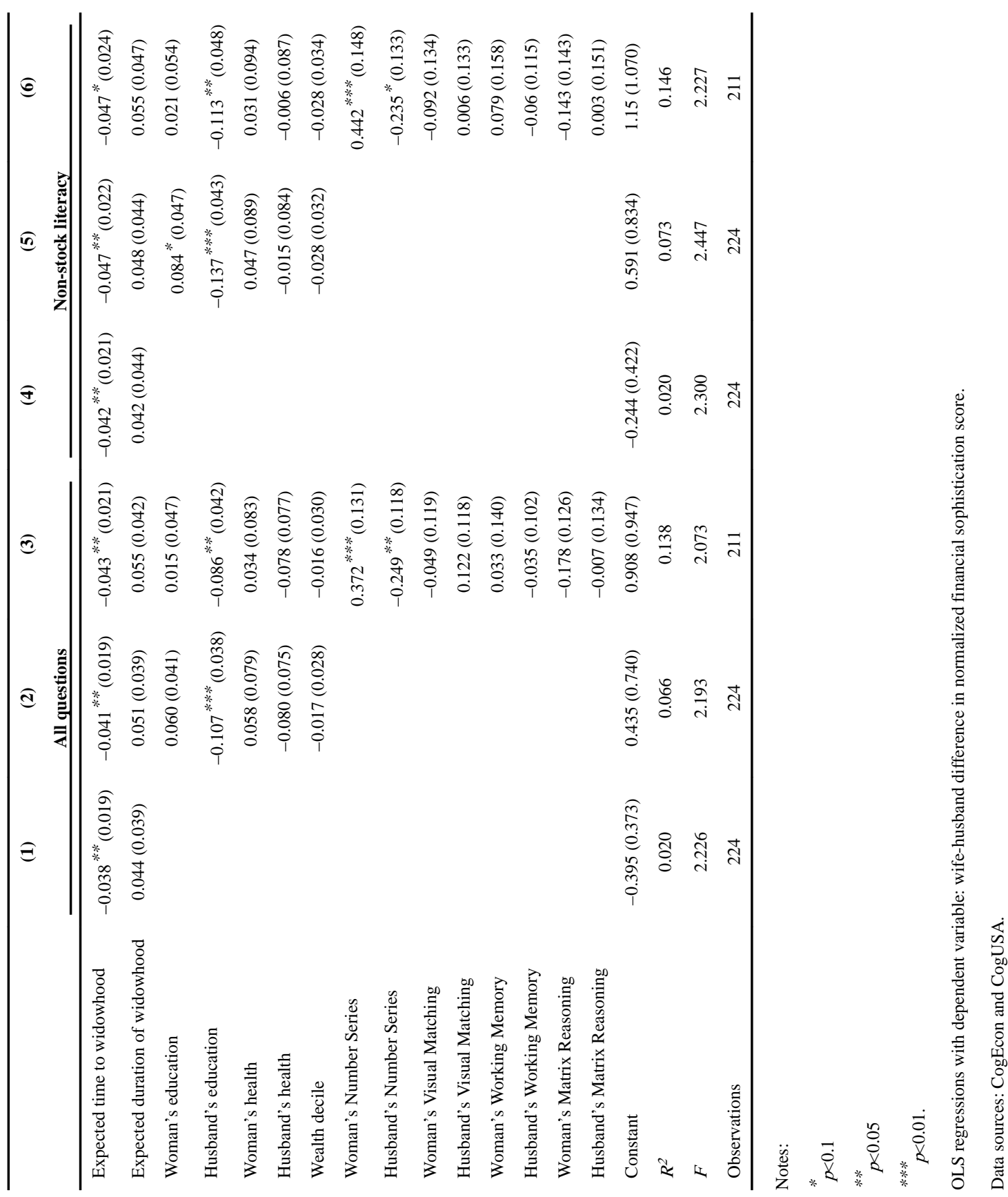

J Hum Resour: Author manuscript; available in PMC 2017 January 30. 


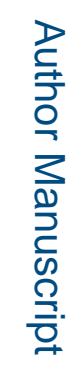

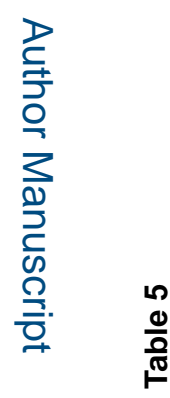

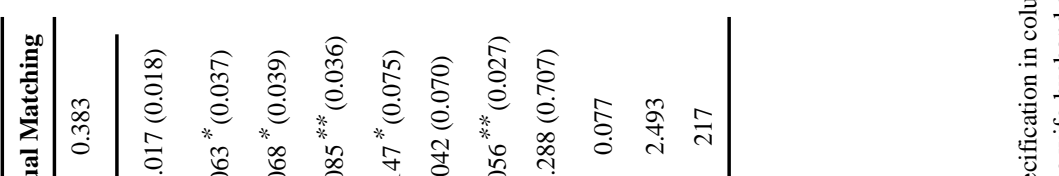

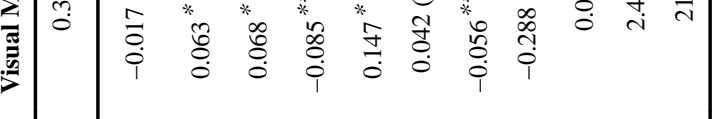

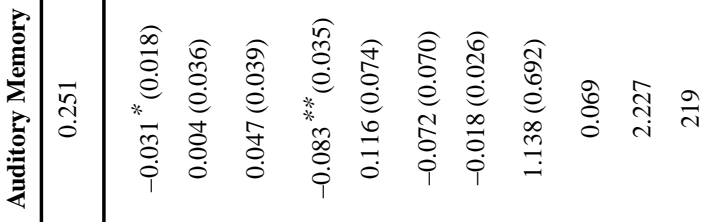

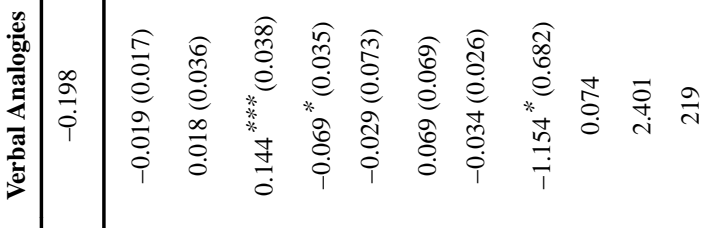

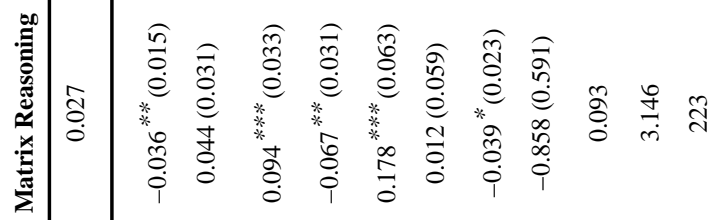

要

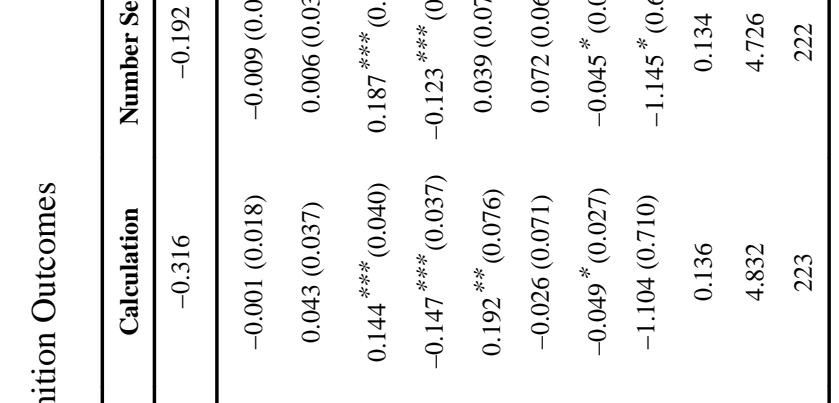

政

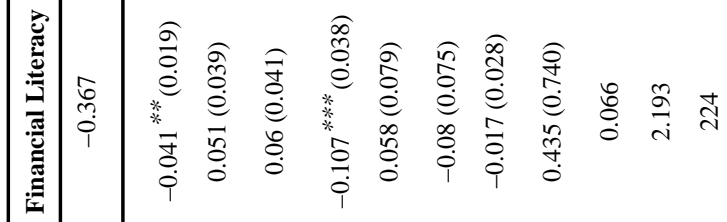

J Hum Resour: Author manuscript; available in PMC 2017 January 30. 


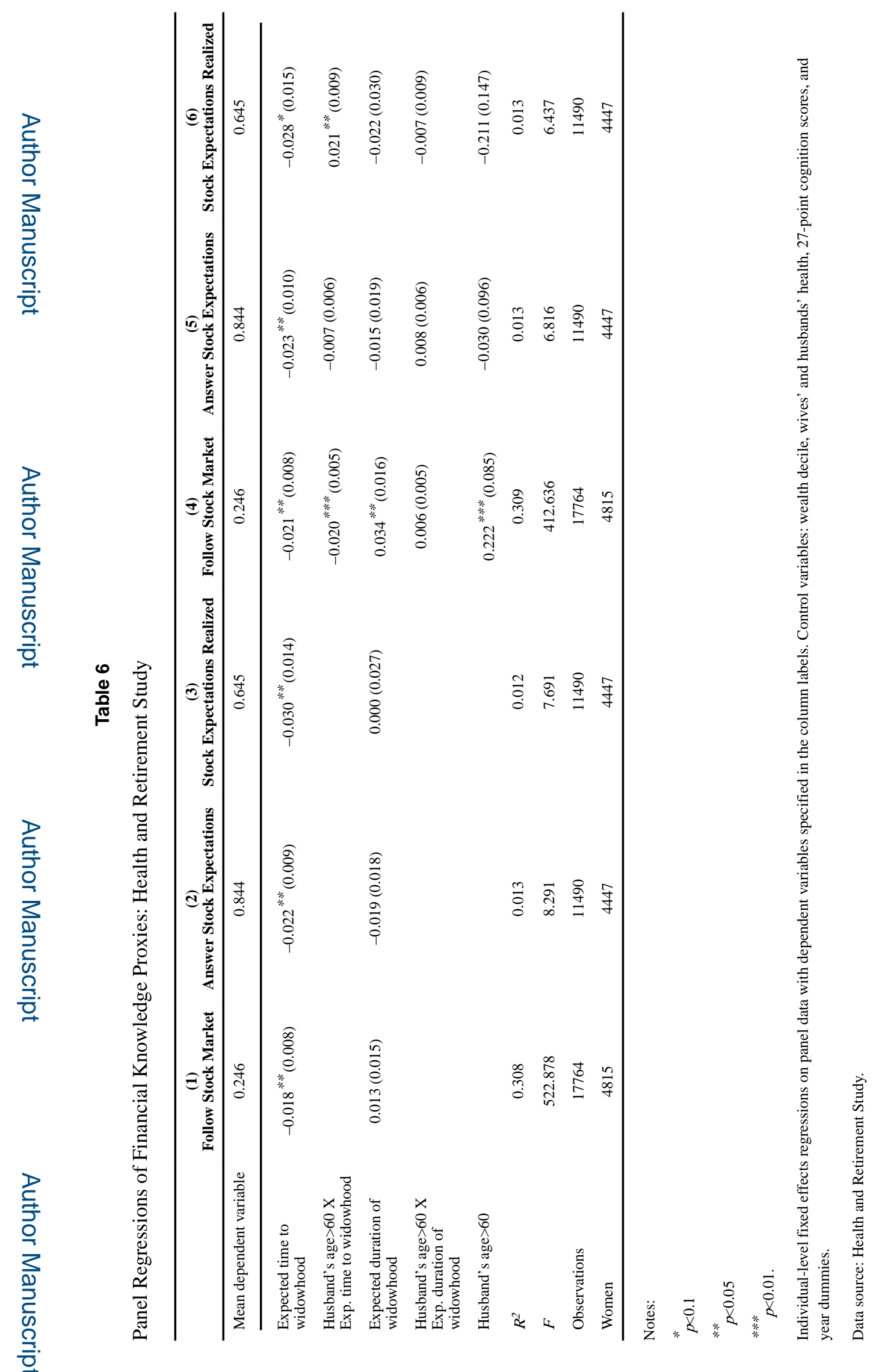

J Hum Resour: Author manuscript; available in PMC 2017 January 30. 

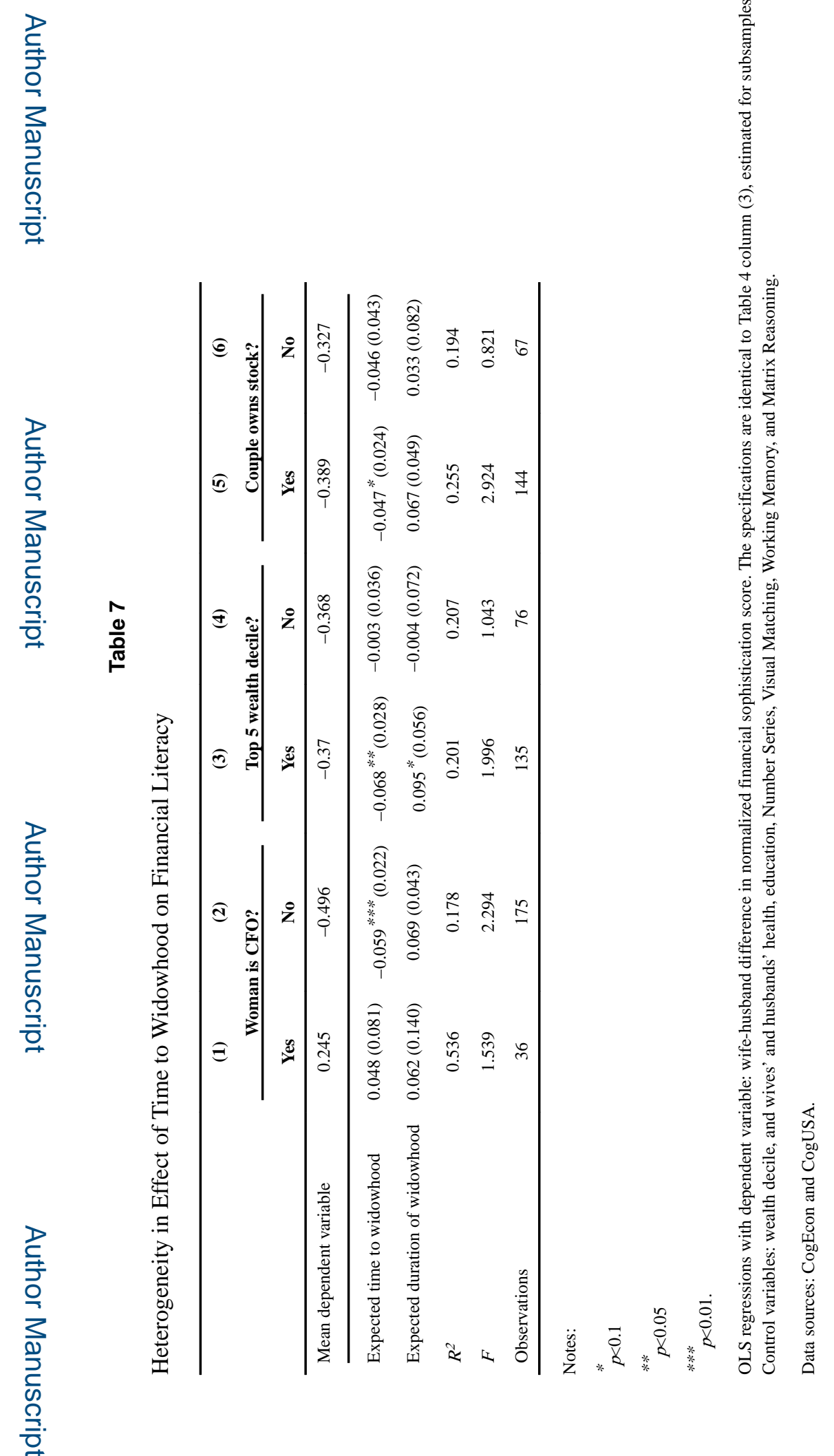

J Hum Resour: Author manuscript; available in PMC 2017 January 30. 